\title{
BLOCKCHAIN FUTURES IN CRYPTOCURRENCIES, TRADE AND FINANCE: A PRELIMINARY ASSESSMENT
}

\author{
Ahmet Faruk Aysan*, Behar Sadriu**, and Humeyra Topuz ${ }^{* * *}$ \\ *Islamic Finance and Economy Program, Hamad Bin Khalifa University, CIS, Qatar. \\ Email: ahmetfarukaysan@gmail.com \\ ** Department of Politics and International Studies, SOAS University of London, London, UK. \\ Email: behar.sadriu@soas.ac.uk \\ *** Department of Business and Finance, Business School, Universidad Carlos III de Madrid, Spanyol. \\ Email: htopuz@emp.uc3m.es
}

\begin{abstract}
The study explores whether blockchain technology can change the paradigm of the current financial structure and the balance of power in the international financial system. Accordingly, this study reviews the development of blockchain technology by analyzing China and Venezuela, both of which struggle to harness their technological advancement and to enhance their power in the international realm. We found that Venezuela invests in blockchain technology to create an alternative payment structure for survivability, while China's desire is to become a global leader in global blockchain technology.
\end{abstract}

Keywords: China; Venezuela; Blockchain; Disruptive technologies; Bitcoin; Central banking. JEL Classifications: C30; E58; G28; O35.

Article history:

Received : January 04, 2020

Revised : June 04, 2020

Accepted : October 29, 2020

Available online : December 31, 2020

https://doi.org/10.21098/bemp.v23i4.1240 


\section{INTRODUCTION}

This paper is speculative to the extent that it seeks to account for some of the potential roles of blockchain technology in disrupting the current structure and balance of power in the international monetary order. 'Blockchain' is the latest technology to be labeled "dangerous" since the "true believers" in the technology "won't stop until they've remade the world. Some of it will be thrilling. Some of it will keep us up at night" (Ford, 2018). Waking up to this reality, global firms are investing resources and energy into thinking about the impact of this on their own industries, from finance to artificial intelligence (AI), robotics, energy and cybersecurity. This is because it has the potential to disrupt what Howard Philip calls the coming era of 'Pax Technica' - an epoch of predictable stability based on known rules and expectations, while confirming his expectation that battles would continue to be waged between rival network infrastructure and norms of internet use (Howard, 2015). States are also increasingly evaluating how technology can be harnessed to increase their power in an international financial system dominated by a few (Ehrlich, 2018). Some, like Venezuela, seek to harness the technology to bypass economic sanctions, while bigger powers like China are more ambitious and pursue ways to accrue relative advantages over rivals in a fast-changing digital space (Ehrlich, 2018). In China today, a state increasingly investing in blockchain futures, this inability to control one application of a technology in the form of cryptocurrencies without taking down the entire internet is one of the Communist Party's main concerns (Ehrlich, 2018).

In this paper, we investigate whether blockchain technology can change the paradigm of the current financial structure and the balance of power in the international financial system. Following this question, new solutions based on blockchain will also allow for new digital tools that challenge the current global hegemonies by opening up new spaces for the bypassing global financial institutions and the power of the hegemonic currencies to develop, thus giving greater influence to weaker and developing states like Venezuela. For states like China, research into blockchain technology is being aggressively pursued to gain relative advantages in the global financial system dominated by western actors. These two case studies are chosen because they represent arguably the biggest challenges to existing global financial orthodoxy, as in the case of China, and also the propensity of frequently maligned rogue regimes like Venezuela to seek out creative solutions to bypass sanctions and to maximize their power.

This paper also opens a discussion on how the states, which have a different financial market structure, in regard to competitive market capacity as compared to their counterparts, are experiencing the blockchain development process. This is because China and Venezuela intend to take advantage of the greatest potential impact of blockchain technology on the traditional financial market (The People's Bank of China, 2019). Although there are several studies on blockchain technology and individual investors, crypto enthusiasts' investments and valuation of cryptoassets in the crypto stock market, we still have very little understanding of how states with a different market structure in an international financial world are experiencing transformation and development of blockchain more systematically. For this reason, our study seeks to understand the development of the blockchain technology in states with different financial, social, and economic backgrounds, by 
undertaking a comparative analysis of China and Venezuela. This study provides a deeper understanding of critical issues, opens up new directions and questions for future research, and perspectives based on the countries' unique experiences and knowledge.

Venezuela has a less competitive financial system relative to China's. Besides, the country is battling hyperinflation and, thus, cash is useless in its current financial structure (Narayan, 2020) ${ }^{1}$. For instance, in 2020, a cup of coffee costs 30,000 bolivars compared to 450 bolivars in 2019 (Laya and Yapur, 2020). Also, the bolivar depreciated by 99\% against the US dollar in 2019 (Laya and Yapur, 2020). Because of these financial problems, Venezuelans are searching for alternative financial solutions more than ever, as an alternative survival strategy. Accordingly, Venezuela's President, Nicolás Maduro, launched a national cryptocurrency called Petro in February 2018, which is backed by the country's oil reserves, to gain confidence for economic growth (Samson, 2018). On the contrary, China, even as one of the most powerful and largest developing countries in the world, embraced blockchain technology to circumvent current financial systemic restrictions and to become the global leader in blockchain technology (Manganiello, 2019). Both China and Venezuela desire to fend off current financial system restrains by investing in digital cryptocurrencies, albeit they do not have similar characteristics, standards, market structure, and the scope of power in developing blockchain technology. Both cases show that, even though blockchain technology is in its nascent stage, applications of blockchain technology in finance and trade have the potential of altering global financial transactions among the countries. Accordingly, these observations raise the following questions: What is the intrinsic value of cryptocurrencies? Why do countries invest in blockchain technology? What frictions make individuals more confident in encrypted currencies rather than fiat money backed by governments/states? What policies and initiatives strengthen the potential impact of blockchain technology in the financial technology space? In this study, we address these questions using theories and empirical examples.

This study primarily extends the literature on adopting a realist international financial framework for analysis based on attempts by states to maximize their power in the international realm. One of the main departures of our examination from the literature is to understand concepts about cryptocurrencies and blockchain technology and their provisions in the global financial system. Before analyzing our cases (China and Venezuela), we underlie concepts under blockchain technology in detail. Since blockchain technology has many sophisticated terms and concepts, underlying fundamental characteristics of blockchain technology will permit us better understand the logic of blockchain technology and cryptocurrencies. When concepts and terms regarding blockchain become clear, the contribution of the study will be better perceived. Accordingly, this study is organized as follows. We first consider three initial ways to think about blockchain technology and its impact on the global financial order: (i) one is through cryptocurrencies and (ii) two is its impact on global trade. We then look specifically at how China and Venezuela are approaching the blockchain technology. Finally, we complete with some other

1 The current COVID-19 pandemic, which has disrupted global economies and financial markets (see Iyke, 2020; Narayan, 2020; Sharma, 2020), will only worsen Venezuela's economy. 
preliminary thoughts on how blockchain technologies may be harnessed and (mis)used by states.

\section{CONCEPTUALIZING TECHNOLOGY AS POWER}

Technology has always been thought of as part of the panoply of resources a state has in its inventory to reach its desired goals. These goals have been stated in the literature to be aimed at security and power in a world thought to be guided by shifts in balances of power (Mearsheimer, 2001; Waltz, 1979, 2000). States jostle for influence in an anarchical international system bereft of hard and fast rules about how best to secure your survival and, more importantly, in the absence of one rule enforcer that can ensure peace (Mearsheimer, 2001). Might is right in a game of survival and any military or technological advantage, which can be gained in securing your interests is a rational response necessary to achieve this. Though neoliberal scholars contend that such anarchy can be 'tamed', through cooperation, international organizations and trade that bind states together, even here the focus is on maximizing gains but not in a winner takes all (relative) gains scenario but in terms of absolute gains that foster cooperation (Martin and Simmons, 1998). To become powerful states must maintain independence in strategic areas like the economy. Our research shows how states like China and Venezuela have reacted to the potentials offered by blockchain technology, suggesting that they are very much in search of relative advantages in their aggressive pursuit of solutions to evade what they see as the unfair 'rules of the game' imposed by existing global structures. Blockchain technology offers them a chance to bypass some of these rules, create new ones and reap the rewards of early adoption.

It is useful here to clarify how we understood technology, since concepts frame things, giving definitions and meanings to ideas and allowing us to speak to each other to better understand how social, political and economic processes evolve. An important introduction to how we should think about technology comes from Charles Singer and his masterful multi-volume work, A History of Technology where he attempts to understand technology as "how things are commonly done or made ... (and) what things are done or made" (Singer et al., 1979). Similarly, others have argued that "broadly speaking, technology is the way people do things" (White, 1940). Therefore, we can settle for a definition of technology as centering on "how humans do things' or, 'how humans get things done." (Dator et al., 2015). We should appreciate here that any changes in the way humans do things or how they get things done presently is of interest to a broad array of scholars: sociologists and their attempts to explain a change in society, historians and their concern for the past and its present implications, economists, too, but also political scientists and their concern for power. It is these last two aspects that we focus on in this study. To be clear, states have always taken a keen interest in technological change and its implications for their rule, whether local or international (Andreas and Price, 2001). States invest billions every year to gain military-technical superiority over rivals and increasingly to surveil their own populations as policing is increasingly militarized in part to the transference of military technology to the former (Andreas and Price, 2001). This is because technology has always presented opportunities and challenges to social, political and economic structures throughout history. 
This has led to many critics, notably Heidegger who argued in his influential critique The Question Concerning Technology that "everywhere we remain unfree and chained to technology, whether we passionately affirm or deny it" (Heidegger, 1977). It was, he argued, only by recognizing its danger that we can 'escape this bondage' (see Blitz, 2014). ${ }^{2}$ In more extreme cases, people like Kaczynski (1995), the infamous 'Unabomber' who ran a bombing campaign across the US between 1978 and 1995, argued that technology was wrecking horror on mankind and needed to be stopped by any means necessary.

Technology is often charged with disrupting the world: criminals', the military's and militants' use of the internet continues to be a major theme when discussing technological revolution (Cleaver, 1998). Consider, for example, the United Kingdom's National Security Capability Review in 2018, which made wide references to cybercrimes - that is, innovative ways to disrupt social, political and economic systems through the internet-as needing urgent investigation since threats which were materializing quicker than had been imagined in an earlier review by the same organization. Technology is thus thought about in terms of power gains, relative advantages and risks.

That technology companies and those who fund them have always thought about such linkages between technology and power is readily apparent if we look at the history regarding how the internet came into being. The US military, for example, helped fund the technology, which eventually gave us the internet in part to its interest in advanced communication tools (Naughton, 2016). Moreover, US agencies like the Central Intelligence Agency and the National Security Agency heavily backed the now global corporation, Google, in its start-up to retain intelligence superiority over its rivals (Ahmed, 2015). The fruits of this were deployed in Iraq and elsewhere. The internet infrastructure has given rise to other technologies, which have profoundly shaped, or disrupted if you like, our world: Google, Facebook, Twitter, PayPal and many others. Moreover, it has allowed for new security threats to emerge thanks to its transformative impact on communications and the ability for group mobilization (Cleaver, 1998).

\section{STATED AND BLOCKCHAIN}

A. Analysis by States

We investigate the blockchain development process in two countries: China and Venezuela. We choose China because its growth rate in science, technology and economy even in the nascent term of blockchain technology is more expeditious as compared to other developing countries. China is important because of its massive economic power (with its global companies in the top ten of Fortune 500), its dynamic youth population density, its global ambitions, and its early massive investment in researching blockchain potentials (Wang et. al., 2019). On the other hand, Venezuela is an interesting case because it is subject to sanctions by the both the US and the European Union (EU), who together lead global financial flows; Venezuela has worked hard over the past decade to evade these sanctions and

2 Source: https://www.thenewatlantis.com/publications/understanding-heidegger-on-technology accessed on 05 August 2020. 
most recently turned to blockchain technology (Karsten and West, 2018) and thus presenting an intriguing insight into current and potential future trends. People, who are living in Venezuela, are seeking alternative payment methods to be able to integrate themselves into the global financial system against international economic sanctions. Meanwhile, endless financial crises in Venezuela inspired people to search for crypto-assets as an alternative payment tool to sustain their survivability. Regarding these underlying facts in today's modern financial structure, we extended our study by analyzing China's and Venezuela's blockchain developments. Although their challenges and strategies to compete against other financial systems appear quite distinct from each other, the remedy that they applied for their financial empowerment is alike, which is blockchain technology.

\section{A1. China}

China is proactively carving out a sphere for itself in the digital sphere to enhance its status as a great power. Indeed, achieving such a status is acknowledged domestically as requiring military power, but also that "marketization, revolutionary advances in information technology, and internationalization are becoming the foundations of national strength" (Rozman, 1999). It is precisely this advancement in information technology, which is today a key aspect of China's march towards global authority, while much of the literature tends to focus on domestic attempts to control its population via advanced technology. The contours of this quest for power go much further, especially in its bid to carve out a sphere of influence in the digital sphere as a necessary addition to its military and economic might. Indeed, China initially accepted the wave of globalization in the 1990s as a necessary part of its own development quest, but soon realized it was a "double-edge sword" that, if mismanaged "could very well derail China's quest for great-power status" (Deng and Moore, 2004). Events like the Asian financial crises between 1997 and 1998 "reinforced suspicion that the United States and Japan seek every opportunity for strategic gain, even in ostensibly economic matters" and the "severe imbalances and inequalities" that persisted in the international system (Narayan, 2020). Beijing, moreover, "did not see itself as immune to the vagaries and injustices associated with contemporary international economic elations", according to Deng and Moore (2004). At the same, China also aggressively sought to promote its economic ties with African and Latin American states and to provide an indirect contest to the US efforts to build a global liberal order that caters for its national interests (Breslin, 2016). Considering these national self-interests, China seeks to salvage its economy from orthodox financial system regulations by empowering its blockchain economy by focusing on two main areas: 1) Empowering blockchain enterprises and blockchain projects led by the Chinese government, and 2) prioritizing research and development to empower China's blockchain development. 


\section{A2. Blockchain Enterprises and Blockchain Projects Led by Chinese Government}

Financial risks and opportunities - and a keen eye for how these relate to its power globally - have pushed China to invest heavily in blockchain research, especially as this relates to overcoming the current dollar-dominated financial system's inherent restrictions (Zhao, 2018). Assessing China's initiatives and eagerness to explore decentralized cryptocurrencies is worthwhile in terms of appreciating the country's future economic course in its international financial agenda.

China has already made a distinguished name for itself in the business sphere for its powerful technological firms and advanced digital payment systems. The rise of firms like Huawei and its role in bringing advanced 5G technology to global consumers shows how Chinese companies have both managed to gain a foothold in international markets (Hooker and Palumbo, 2019).

Accordingly, epitomizing the role China has assigned to blockchain research, China's Central Bank (PBoC) has funded an advanced research group in 2016 for national digital currency to scrutinize the strategic objectives of digital currencies and initial coin offerings by connecting with specialists of Citibank and Deloitte (The People's Bank of China, 2019). PBoC's main objective is to decrease operating costs, gain greater efficiency and to check for unlawful money flows (Das, 2016). Fan Yifei, the vice governor of the PBoC indicated that PBoC's main agenda is going to be concentrated on digital currency and development to guarantee the empowerment of the Chinese yuan in the international financial system (The People's Bank of China, 2019). The consolidation of China's national currency is a strategic priority, which the country hopes will provide leverage against the US dollar (Zhao, 2018). PBoC research centered on new cryptocurrencies and blockchain technology and is already a work in progress; China is poised to emerge as a pioneer for these innovations in a supervisory role (Campbell, 2016). This will involve their own private encrypted currencies and creating digital legal tenders of their own (Campbell, 2016).

Additionally, reports from the Chinese Academy of Social Sciences, a top government think tank, argue that digital currencies as an international payment system should be adopted by central banks to decrease transaction time and costs (Reuters, 2018). Zhou Xiaochuan, who was the governor of the People's Bank of China, affirmed that digital currencies have practical revolutionary functions as a payment system in terms of their speed, reliability and inexpensiveness. ${ }^{3}$ To set up cryptocurrencies for financial regulations, Fan Yifei, a vice central bank governor has offered a strategic policy for China to carry a two-tier system, which consists of the central bank and financial institutions as a legitimate issuer. ${ }^{4}$ All in all, China's Central Bank is in the process of integrating its financial system into the blockchain economy to protect its national currency and diversify its financial revenues against dollarization.

Looking at the last couple of years of research by People's Bank of China and at China's latest blockchain projects, it can be observed that China conducts

3 Source: https://www.bloomberg.com/news/articles/2018-03-09/cash-may-disappear-in-china-aspayments-go-digital-pboc-says?utm_content=crypto\&utm_campaign=socialflow-organic\&utm _ source=twitter\&utm_medium=social accessed on 05 August 2020.

4 Source: https://www.reuters.com/article/us-china-crytocurrency-cenbank/central-banks-shouldconsider-using-digital-currencies-china-think-tank-idUSKBN1FR0ZL accessed on 05 August 2020. 
a real-world pilot project. It is backed by the government in different major cities in Shenzhen, Suzhou, Chengdu, and Xiong. This new currency is tested it in these specific locations before introducing it to the public with the aim of altering paper money and coins in circulation. Limiting this project to the urban cities allows China to monitor its impact on the public in a more manageable way. Different from other blockchain projects, the PBOC's main aim is not to create a decentralized cryptographic financial system. On the contrary, PBOC's main aim is to generate a highly centralized digital financial system under its control by removing intermediaries in the system (Jia, 2020). Accordingly, China's other latest blockchain project is Blockchain-based Service Network (BSN) as initiated in April 2020 in Beijing (Wang et. al., 2019). In this network, Chinese state officials provide an integrated global infrastructure for enterprises to be able to generate new blockchain applications in a less costly way (Wang et. al., 2019). For this project, China Mobile, China Union Pay, and Huobi China worked together with the intent to bolster the digital economy for developers from all around the world. BSN is a global project as a national priority, which Xi Jinping (the country's leader) desires to open the doors to the world technology giants to catch their investments in China (Stockton, 2020).

More specifically, we can extend China's new developments by looking at the country's intellectual property output in statistics. For instance, patents are very important indicators of creativity of the companies, especially for innovative technology. Statistically, when we consider China's number of patents, there are more than 10,000 blockchain-based patent applications in China National Intellectual Property Administration (CNIPA) (World Intellectual Property Organization, 2020). Meanwhile, China applied the highest patent cooperation treaty applications in 2019 (Figure 2). Alibaba has been ranked first, in terms of patent applications, having applied for 543 patents (World Intellectual Property Organization, 2020). Secondly, Unicom, which is a state-own telecom company has 214 patents (Forkast, 2020). Hence, given these examples, we can state that China encourages enterprises to produce more innovative and creative blockchain projects in global standards, even though they have strict economic regulations for investors and they banned cryptocurrencies in 2017 to control non-regulative crypto projects (Seth, 2019). 


\section{Figure 1. \\ International Patent Applications by Country}

The figure shows international patent applications by country. The data comes from the World Intellectual Property Organization (2020).

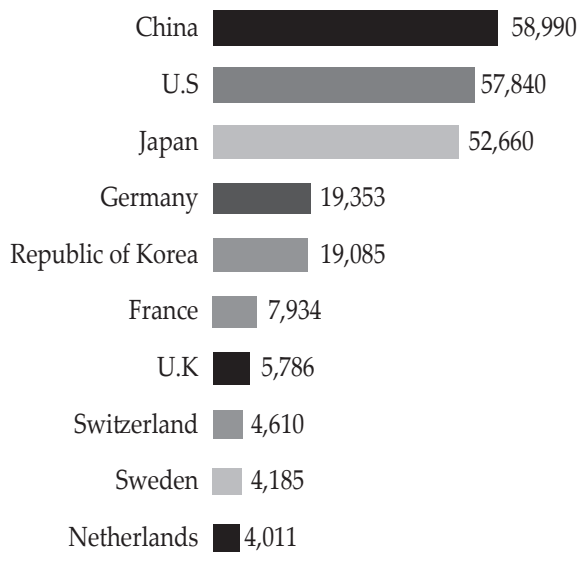

2019

A3. The Role of Research and Development in China's Blockchain Development

Each country should make its cost-benefit and SWOT analysis to fabricate true and original innovation instead of copying others based on their own technological and financial requirements in their financial agenda. To do this, academic scholars, high-tech engineers, statisticians, and mathematicians play a crucial role in increasing the quality of research and development. As can be seen in Table 1, China has advantageous soft power in terms of high-yielding research institutions in global blockchain research. Accordingly, Chinese institutions and pundits have distinguished success; more than half of Chinese research institutions have been ranked in the top 20 world research institutions studying blockchain (Wang et al., 2020).

Table 1.

List of Top 20 World Research Institutions Studying Blockchain

The table shows the top 20 world research institutions. The list is taken from Wang et al., (2020).

\begin{tabular}{lcc}
\hline Research İnstitutions & Full Name & Countries \\
\hline Beijing Univ Posts \& & Beijing University of Posts and Telecommunications & China \\
Telecommunications & Chinese Academy of Science & China \\
Chinese Acad Sci & Austrian Commonwealth Scientific and Industrial & Australia \\
CSIRO & Research Organization & \\
Univ Elect Sci \& Technol & China University of Electronic Science and & China \\
China & Technology & China \\
Tsinghua Univ & Tsinghua University & China \\
Beihang Univ & Beihang University & Singapore \\
Nanyang Technol Univ & Nanyang Technological University &
\end{tabular}


Table 1.

List of Top 20 World Research Institutions Studying Blockchain (Continued)

\begin{tabular}{lcc}
\hline Research Institutions & Full Name & Countries \\
\hline Xidian Univ & Xidian University of Electronic Technology & China \\
Shanghai Jiao Tong Univ & Shanghai Jiao Tong University & China \\
IBM Res & IBM Research & USA \\
Univ Chinese Acad Sci & University of Chinese Academy of Sciences & China \\
Natl Univ Def Technol & National University of Defence Technology & China \\
UCL & University of London & England \\
Univ Sydney & University of Sydney & Australia \\
Peking Univ & Peking University & China \\
Sun Yat Sen Univ & Sun Yat-sen University & China \\
Univ Cagliari & University of Cagliari & Italy \\
Guangdong Univ Technol & Guangdong University of Technology & China \\
Natl Univ Singapore & National University of Singapore & Singapore \\
Univ Texas San Antonio & University of Texas at San Antonio & USA \\
\hline
\end{tabular}

Furthermore, World Bank's statistics show that China has upgraded its gross domestic expenditure on research and development projects, which comprise experimental development, applied and basic researches, from 1996 to 2018 (Wang et al., 2020). Besides, China supports its intellectuals, pundits, and researchers through subsidies to enable them catch up their global counterparts (Wang et al., 2020).

Besides, the Chinese government has released its 15-year blueprint in 2020, which announces the country's global technological advancement agenda (World Intellectual Property Organization, 2020). In this initiative, China's main motivation is to build a resilient technological system against conflicts and ambiguities for future technologies including blockchain (Wanxiang Blockchain Labs, 2019). As reported by the Lagou Institute of Big Data research, currently $86 \%$ of the employees who are working in Chinese institutions are identified as suitable candidates for future jobs (Tran, 2020). Hence, there will be a sizeable talent gap in China, which is statistically reported as 4.2 million people at the end of 2020 (Tran, 2020). Therefore, to empower China's technological infrastructure, the country is preparing its institutions by reducing the talent gap between required positions and talented experts who can professionally adapt to the next creative disruptive technologies and to manage risky circumstances for the long-term technological projects (Tran, 2020). For instance, a diversified network of universities and incubators are playing a pivotal role in their development agenda (Tran, 2020). To reduce the talent gap, not only are they creating a diversified network in universities and incubators in various centers but China is also constructing blockchain laboratories and hackathons that provide more dynamic, innovative and explorative communities within these institutions (Manganiello, 2019). Concerning this aim, some of the recent global blockchain events that happened during the Shanghai International Blockchain Week 2019-Hackathon (on 14-15 September), Demo day for global projects and the $5^{\text {th }}(16$ September) Global Blockchain Summit (17-18 September) - prove China's endeavors in this way (Wanxiang Blockchain 
Labs, 2019). The world's best blockchain teams came together from various sectors and shared their vision, potential impacts, applications and relatively competitive goals with other teams and quests (Wanxiang Blockchain Labs, 2019).

Considering all these, China gave importance to the interactions and collaborations among scientists and entrepreneurs within a diversified network of universities and incubators. When China adapt its institutions to more innovative and durable places in global and more advanced standards against the future potential creative destructive technologies, resorting to science will give the country power to promote consensus among politicians, entrepreneurs and intellectuals in a more rational and systematic thinking way. Hence, this will create a more innovative and dynamic atmosphere where people can share their experience contribute to China's economic growth in a less costly and efficient way. The research and developments in their diversified network also provide institutions long-term survivability even in risky and financial crises times.

\section{B. Venezuela}

Unlike China, Venezuela has since 2010 plunged into a major economic crisis, compounded by domestic infighting between the socialist government of first, Hugo Chavez and, then, Nicolás Maduro and the opposition (Laya and Yapur, 2020). Hyperinflation and food shortages, on top of the country's inability to engage fully in international financial markets due to US sanctions, have hit the country hard Berman, A. (2018). Like China, Venezuela has also invested in blockchain research to alleviate what it believes is an unfair economic system holding back its progress.

Venezuela is primarily interested in blockchain to create a new digital currency to raise global funds, bypass US and EU sanctions and offer an alternative to its domestic currency, the bolívar (Karsten and West, 2018). To this end, the country launched its own cryptocurrency called petro in 2018 (Berman, 2018). The aim was to attract foreign investors, who could not have approached the country via conventional means, and, in the end, it raised $\$ 700$ million in its initial offering (Berman 2018). Venezuela has also vowed to "that it will accept Petros as a form of payment of national taxes, fees, contributions and public services" (Samson, 2018). Via initial coin offerings, the state was able to raise money and bypass international banking restrictions. This follows intense research by other countries, most notably, Sweden and its central bank, Sveriges Riksbank (2019), about the viability of releasing an 'e-krona', which would be equivalent to its regular currency (Sveriges, 2019). In Venezuela's case, the country petro is begged to the price of oil in a bid to lure investors and raise foreign currency supplies (Browne, 2018).

Sensing the dangers, the influential US-based Brookings Institution released a report deriding this development, arguing that "it is relatively unsurprising that a dictatorship with little reserve currency ... has resorted to a deceitful means like introducing the petro ... [t] he petro ... exists to create foreign currency reserves from thin air" (Karsten and West, 2018). Going forward there is the very real prospect here for other states to follow suit and "create a cryptocurrency tied to a government-controlled asset, raise money in violation of sanctions, and proceed to manipulate that cryptocurrency's value to maximizing profit" as Karsten and 
West (2018) argued at the center for Technology Innovation. Cryptos thus erode the power of sanctions by exploiting the newness of the technology and potential ambiguities.

Recognizing how this technology weakens its power to punish what it considers rogue elements in the international system, US financial regulators began considering taking ownership of the petro coin illegal due to sanctions and noted that "in light of recent actions taken by the Maduro regime to attempt to circumvent U.S. sanctions by issuing a digital currency in a process that Venezuela's democratically elected National Assembly has denounced as unlawful, hereby order as follows: Section 1. (a) All transactions related to, provision of financing for, and other dealings in, by a United States person or within the United States, any digital currency, digital coin, or digital token, that was issued by, for, or on behalf of the Government of Venezuela on or after January 9, 2018, are prohibited as of the effective date of this order." ${ }^{5}$ It can be said that the current economic woes impacting Venezuela due largely to a worthless national currency, the lack of financial services, hyperinflation rates and the massive national debt have pushed the government to create alternative payment tools to fend off financial and political sanctions that the US has imposed on it.

By harnessing the power of blockchain, Venezuela was able to create a new instrument to bypass existing financial systems. Petro thus became the first formal cryptocurrency in this ecosystem. Despite its obvious failures - low uptake from citizens, for example - other efforts were made to stabilize and take control of the worsening economy, including revamping petro coin's functions (Berman 2018). For example, a new petro public sale began on November 5, 2018, as stated by Venezuelan president Nicolas Maduro on national television (Berman, 2018). The differences between the revamped and old petro is that the newest one is not going to be backed just by oil but by $10 \%$ diamond, $20 \%$ gold, $20 \%$ iron and $50 \%$ oil resources (Berman, 2018). This will help to remove one of the key concerns for cryptocurrency investors, which is price volatility. In a bid to further force citizens to use the coin, an updated white paper stated that in the future passports in Venezuela can only be purchased with the revamped petro and it will cost 7.200 bolivars (equivalent to two crypto petros). ${ }^{6}$

Acutely aware of their subordinate position in an international system dominated largely by actors who sanctioned it and with an increasingly hostile regional environment, Venezuela has sought to create solutions to bypass financial systems entirely. The Venezuelan government is in search of alternative payment systems to save their country from the intensifying economic meltdown, humanitarian crises and to circumvent US sanctions (Karsten and West 2018).). Petro, as a decentralized cryptocurrency, is pitched as a legal substitute for dollars. Practically speaking though, only time will tell us how successful petro can be in recovering Venezuela from the current deep economic crises it is mired in. Doubts remain, however, about its viability owing to its centralized (state) nature making

\footnotetext{
5 Source: https://www.whitehouse.gov/presidential-actions/executive-order-taking-additional-stepsaddress-situation-venezuela/ accessed on 05 August 2020

6 More information, see: https://www.bloomberg.com/news/articles/2018-10-05/crypto-now-the-onlyway-isolated-venezuelans-can-buy-passports accessed on 05 August 2020.
} 
it just as suspicious for Venezuelans as the practically useless official currency, the bolivar. Yet, this does not mean the end of blockchain or cryptocurrencies in the country. Venezuelans continue to trade massively in bitcoins, especially as economic conditions worsen. ${ }^{7}$ The US Treasury Department was so alarmed by the financing of petro that it recently put Moscow based Evrofinance Mosnarbank on its sanctions list for helping Venezuela in this (Mohsin, 2019). Still, many obstacles remain for Venezuela, however, and it is clear from the petro case that for economic reconstruction or remodeling programs of this scale, much of the groundwork educating citizens for one - is required beforehand. The more people are educated, the more petro can be used more efficiently. In addition to this, the government still must overcome any negative perceptions among the public. Only then can the petro be accepted more widely.

\section{CONCLUSION}

In this paper, we offered a preliminary analysis of what blockchain technology is and what some of its applications may be and the implications for the international financial system, specifically the quest for power. We argued that the technology, due to its emphasis on secure peer-to-peer (decentralized) systems, could radically alter key industries in finance. Besides, the technology has broader implications for how states manage the internet. Based on current literature trends, blockchain is seen as either a nightmare - the ability of a massive, public listing of all our transactions - or a liberating tool that can free people from the rigid governing structures currently structuring our increasingly digital lives. From finance to artificial intelligence and global financial systems, global conglomerates and states will continue experimenting with this technology in the coming years.

Although a large theoretical literature exists on the blockchain and other innovative technologies, relatively little research focuses on a comparative crosscountry analysis of blockchain development and especially concentrating on China and Venezuela, two countries with relatively different competitive market structures and scope of power in international finance. In this study, seizing a realist international financial framework, we explored Venezuela and China's attempt to utilize the new technology to maximize their powers and fend off the current international financial system's limitations. Exclusively, we examined the importance of research and development alongside real-world blockchain enterprises and blockchain projects supported by the Chinese government in China's blockchain development. The coexistence of public and private blockchain projects, which are fortified by scientific evidence, gives China endurance and power for its institutions in the development of blockchain technology. We document that China's main aim is opening the country's doors to the world's global leaders in the innovative sector, albeit it strictly regulates its local firms and enterprises. Likewise, China supports its scientists, entrepreneurs and state officials to enhance themselves to global standards. Accordingly, these actors created platforms of diversified networks in universities, research institutions and global

\footnotetext{
Source: https://dailyhodl.com/2019/02/23/venezuelan-says-bitcoin-and-crypto-are-keeping-hisfamily-alive-as-crisis-grows-increasingly-violent/ accessed on 05 August 2020.
} 
blockchain summits located in China to share their knowledge and experiences simultaneously. China has already invested significantly in this endeavor, despite its massive economic and technological base, while Venezuela - beset by economic crises and a powerful foe in the form of the US - is also seeking ways to bypass the dollar-based financial order utilizing a national cryptocurrency of its own. Hence, Venezuela does not have systemic and corporate financial blockchain developments as does China. Both countries' main purpose is to create an alternative financial system for their survivability. In both cases, this exciting new technology has the potential to revolutionize the way global financial transactions are processed. Hence, Venezuela and China are trying to create their own alternative realities by courtesy of blockchain technology's creative destruction power and adopting a realist international realm.

\section{REFERENCES}

Ahmed, N. (2015). How the CIA made Google. A Medium Corporation. Retrieved from: https: //medium.com/insurge-intelligence/how-the-cia-made-googlee836451a959e.

Andreas, P., \& Price, R. (2001). From war Fighting to Crime-Fighting: Transforming the American National Security State. International Studies Review, 3, 31-52. https://doi.org/10.1111/1521-9488.00243.

Berman, A. (2018). Venezuela's Controversial Petro Sale Starting November, Maduro Claims Cointelegraph. Retrieved from: https:/cointelegraph.com/news/ venezuelas-controversial-petro-sale-starting-november-maduro-claims.

Blitz, M. (2014). Understanding Heidegger on Technology. The New Atlantis A Journal of Technology and Society, 41, 63-80. Retrieved from: https://www. thenewatlantis.com/publications/understanding-heidegger-on-technology.

Bloomberg News (2018). Cash May Disappear in China as Payments Go Digital, PBOC Says. Bloomberg News. Retrieved from: https://www.bloomberg.com/news/ articles/2018-03-09/cash-may-disappear-in-china-as-payments-go-digitalpboc-says

Breslin, S. (2016). China and the global political economy. Springer.

Browne, Ryan (2018). Venezuela's Oil-Backed Cryptocurrency Raised \$735 Million in One Day, President Claims. CNBC. Retrieved from: https://www.cnbc. com/2018/02/21/venezuelan-oil-backed-cryptocurrency-petro-raised-735million-maduro.html.

Campbell, R. (2016). PBOC Vice Governor Says Central Banks Should Lead on Digital Currencies. CCN. Retrieved from: https://www.ccn.com/pboc-vice-governorsays-central-banks-should-lead-on-digital-currencies.

Chen, J., (2020). Digital Currency Trials are Underway. The State Council. The People's Republic of China. Retrieved from: http://english.www.gov.cn/statecouncil/ ministries/202004/21/content_WS5e9e4e02c6d0b3f0e949603f.html.

Cleaver Jr, H. M. (1998). The Zapatista Effect: The Internet and The Rise of an Alternative Political Fabric. Journal of International Affairs, 51, 621-640.

Dailyhodl Staff. (2019). Venezuelan Says Bitcoin and Crypto Are Keeping His Family Alive As Crises Grows Increasingly Violent. The Daily Hodl News and Insight for the Digital Economy. Retrieved from: https://dailyhodl.com/2019/02/23/ 
venezuelan-says-bitcoin-and-crypto-are-keeping-his-family-alive-as-crisisgrows-increasingly-violent/

Das, S. (2016). China's Central Bank Will Look to Issue Its Own Digital Currency "As Soon As Possible". CCN. Retrieved from: https://www.ccn.com/china-digitalcurrency.

Dator J. A., Sweeney J. A., \& Yee, A. M. (2015). Mutative Media: Communication Technologies and Power Relations in the Past, Present, and Futures. Switzerland: Springer. https://doi.org/10.1007/978-3-319-07809-0

Deng, Y., and Moore, T. G. (2004). China Views Globalization: Toward a New Great-Power Politics? The Washington Quarterly, 27, 115-136.

Ehrlich, S. (2018). Making Sense of China's Grand Blockchain Strategy. Forbes. Retrieved from: https://www.forbes.com/sites/stevenehrlich/2018/09/17/ making-sense-of-chinas-grand-blockchain-strategy/\#7c721d4d3678

Ford, P. (2018). Bitcoin is Ridiculous. Blockchain is Dangerous. Bloomberg Businessweek. Retrieved from: https://www.bloomberg.com/news/ features/2018-03-09/bitcoin-is-ridiculous-blockchain-is-dangerous-paul-ford

Forkast. (2020). China is Leading the Global Blockchain Patent Race. Forkast. Retrieved from: https://forkast.news/china-is-leading-the-global-blockchain-patent-race/

Heidegger, M. (1977). The Question Concerning Technology. New York: Harper \& Row, 3-35.

Hooker, L. \& Palumbo, D. (2019). Huawei: The Rapid Growth of a Chinese Champion in Five Charts. BBC News. Retrieved from: https://www.bbc.com/news/ business-46480208.

Howard, P. N. (2015). Pax Technica: How the Internet of things may set us free or lock us up. Yale University Press.

Iyke, B. N. (2020). Economic Policy Uncertainty in Times of COVID-19 Pandemic. Asian Economics Letters, 1. https://doi.org/10.46557/001c.17665.

Kaczynski, T. (1995). Industrial Society and Its Future. The Washington Post. Retrieved from: https://www.washingtonpost.com/wpsrv/national/longterm/ unabomber/manifesto.text.html.

Karsten, J. \& West, D. (2018). Venezuela's "petro" undermines other cryptocurrencies - and international sanctions. Brookings. Retrieved from: https://www. brookings.edu/blog/techtank/2018/03/09/venezuelas-petro-undermines-othercryptocurrencies-and-international-sanctions/

Laya, P. \& Yapur, N. (2020). Venezuela's latest problem is there are now too many dollars. Bloomberg Businessweek. Retrieved from: https://www.bloomberg.com/ news/articles/2020-01-03/venezuela-s-latest-problem-is-there-are-now-toomany-dollars.

Manganiello, F. (2019). How is China Implementing Blockchain Technology? Forbes. Retrieved from: https://www.forbes.com/sites/ fiorenzomanganiello/2019/02/06/how-is-china-implementing-blockchaintechnology/\#231639f541f9.

Martin, L. L., \& Simmons, B. A. (1998). Theories and Empirical Studies of International Institutions. The International Organization, 52, 729-757.

Mearsheimer, J. J. (2001). The Tragedy of Great Power Politics. WW Norton \& Company. 
Mohsin, S. (2019). U.S. Sanctions Russian Bank for Supporting Venezuela's PDVSA.

Narayan, P. K. (2020). Did Bubble Activity Intensify during COVID-19. Asian Economics Letters, 1, 17654. https://doi.org/10.46557/001c.17654.

Naughton. (2016). The evolution of the Internet: from Military Experiment to General Purpose Technology. Journal of Cyber Policy, 1, 5-28. DOI: 10.1080/23738871.2016.1157619.

Reuters Staff. (2018). Central Banks Should Consider Using Digital Currencies: China Think Tank. Reuters. Retrieved from https://www.reuters.com/article/uschina-crytocurrency-cenbank/central-banks-should-consider-using-digitalcurrencies-china-think-tank-idUSKBN1FR0ZL.

Rozman, G. (1999). China's Quest for Great Power Identity. Orbis, 43, 383-402. https://doi.org/10.1016/S0030-4387(99)80078-7.

Samson, A. (2018). Venezuela Launches Presale of State Backed 'Petro' Cryptocurrency. Financial Times. Retrieved from: https://www.ft.com/content/07b1052c-164811e8-9376-4a6390addb44.

Seth, S. (2019). Is Bitcoin Banned in China? Investopedia. Retrieved from: https:// www.investopedia.com/news/bitcoin-banned-china/.

Sharma, S. S. (2020). A Note on the Asian Market Volatility During the COVID-19 Pandemic. Asian Economics Letters, 1. https://doi.org/10.46557/001c.17661.

Singer, C. J., John, \& Holmyard, E. J., and Hall, A. R. (1979). Oxford: A history of technology, vol 1. Clarendon Press. https://doi.org/10.1017/S0003598X00028714.

Stockton, N. (2020). China Launches National Blockchain Network in 100 Cities. IEEE Spectrum. Retrieved from: https://spectrum.ieee.org/computing/software/ china-launches-national-blockchain-network-100-cities.

Sveriges Riksbank. (2019). E-krona. Sveriges Riksbank. Retrieved from: https:// www.riksbank.se/en-gb/payments--cash/e-krona/

The People's Bank of China, (2019). Transcript of Governor Zhou Xiaochuan's Exclusive Interview with Caixin Weekly. The People's Bank of China. Retrieved from: http://www.pbc.gov.cn/english/130721/3017134/index.html.

Tran, S. (2020). China to Dominate Global Tech Standards? Expert says "It would be Tough". Blockchain.News. Retrieved from: https://blockchain.news/analysis/ china-dominate-global-tech-standards-expert-tough.

Waltz, K. N. (1979). Theory of International Politics. New York: McGraw Hills.

Waltz, K. N. (2000). Structural realism after the Cold War. International Security, 25, 5-41. https://doi.org/10.1162/016228800560372.

Wang, Q., Su, M., \& Li, R. (2020). Is China the World's Blockchain Leader? Evidence, Evolution and Outlook of China's Blockchain Research. Journal of Cleaner Production. 1-20. https://doi.org/10.1016/j.jclepro.2020.121742.

Wanxiang Blockchain Labs. (2019). 2019 Shanghai International Blockchain Week. Retrieved from: http://www.blockchainlabs.org/week2019/index_en.html.

White, L. Jr. (1940). Technology and invention in the Middle Ages. Speculum, 15, 141-159. DOI: 10.2307/2849046.

World Intellectual Property Organization. (2020). China Becomes Top Filer of International Patents in 2019 Amid Robust Growth for WIPO's IP Services, Treaties and Finances. 
Zerpa, F. (2018). Crypto Now the Only Way Isolated Venezuelans Can Buy Passports. Bloomberg Technology. Retreieved from: https://www.bloomberg.com/news/ articles/2018-10-05/crypto-now-the-only-way-isolated-venezuelans-can-buypassports.

Zhao, W. (2018). China's Central Bank Eyes Crypto as Possible Yuan Risk. Coindesk. Retrieved from https://www.coindesk.com/chinas-central-bank-eyescryptocurrency-as-possible-yuan-risk/. 
This page is intentionally left blank 